\title{
How sentence type influences the interpretation of Spanish future constructions
}

\begin{abstract}
It is well known that Spanish futurizing morphology, whether synthetic or periphrastic, is frequently used not to express futurity but to formulate a hypothesis, i.e. express epistemic modality, although the synthetic future tense is more likely to express such epistemic reading than the periphrastic future. This paper explores the relationship between futurizing morphology and sentence type on the basis of a quantitative analysis of about $n=2,700$ tokens of synthetic and periphrastic 'future' constructions in spoken conversations from Madrid, Buenos Aires and Santiago de Chile. On the basis of a bottom-up classification of these tokens regarding their potential to express modal meanings, we demonstrate that polar and partial futurizing interrogatives are more likely to display modal meanings and associated rhetorical effects than futurizing declaratives, an effect that is even stronger for synthetic future constructions. This is due to a conventionalization of specific form-function pairings. Finally, we also document substantial dialectal variation in the use of futurizing morphology.

Keywords: tense, modality, epistemicity, evidentiality, Spanish, question
\end{abstract}

\section{Introduction}

It is well known that Spanish futurizing morphology, whether synthetic or periphrastic, is frequently used not to express futurity but to put forth a hypothesis (Escandell-Vidal 2010, 2014, 2018; Rodríguez Rosique 2019, among many others). According to Escandell-Vidal, the use of future tense in examples such as (1) encodes a procedural instruction to interpret the propositional content as the result of an inference by the speaker. As noted by many authors, in Peninsular Spanish the synthetic future tense (1a) is more likely to express such epistemic reading than the periphrastic future (1b).

(1) [the doorbell rings]
a. Será Juan.
be.IND.FUT.3SG Juan
'That must be Juan.'
b. Va $\quad$ a ser Juan.
go.IND.PRS.3SG to be.INF Juan
'That must be Juan.'


The overwhelming majority of previous studies on the Spanish future tenses has focused on declarative sentences such as (1). Interestingly however, the use of futurizing morphology can lead to rhetorical effects, a phenomenon that has not been studied thoroughly (cf. Rodríguez Rosique 2019). Consider, for instance, example (2) taken from the Spanish section of the C-ORAL ROM corpus (Cresti \& Moneglia 2005), in which the speakers PAC and PAT are talking about a house built by some friends. PAT's futureinflected interrogative is used as a rhetorical question, signaling the obviousness of the answer and the irrelevance of PAC's admiration of the house.

(2) casa (C-ORAL ROM, efamcr05)

01

$\begin{array}{lllll}\text { PAC: } & \text { Con una } & \text { terrac-ita } y & \text { todo? } \\ & \text { with det.INDF.F.SG terrace.DIM and everything } \\ & \text { 'With a small terrace and everything?' }\end{array}$

02

PAT: De todo

of everything

'With everything'

03

$\begin{array}{rllll}\text { PAC: Joder eso menuda } & \text { casa est-á-n } & \text { hac-iendo [...] } \\ \text { wow that nice } & \text { house be-IND.PRS.3-PL make-PROG }\end{array}$

'Wow, that's a nice house they are building'

04
PAT: $\quad$ Llev-a-n
dos
tres año-s con la
take-IND-PRS.3-PL
two or
three year-PL with
DET.DEF.M.SG
casa,
¿cómo est-ará $\quad$ la
casa? ilmpresionante!
how be-IND.FUT.3SG DET.DEF.M.SG house impressive
'They have been working on the house for two or three years, how (else) can the house be? Impressive!'

This paper explores the relationship between futurizing morphology and sentence type on the basis of a qualitative and quantitative analysis of about $n=2,700$ tokens of synthetic and periphrastic 'future' constructions in conversations in Spanish from Madrid, Buenos Aires and Santiago de Chile taken from the C-ORAL ROM (Cresti \& Moneglia 2005) and the COLA (Jørgensen \& Eguía Padilla 2017). Our analysis suggests that in Spanish, futurizing morphology impacts the use of interrogatives differently than the use of declaratives. In general, the use of futurizing morphology in its epistemic reading indicates a low 
degree of epistemic commitment by the speaker over the proposition. Because questioning speech acts likewise arise in situations in which the speaker signals that she has low epistemic authority over the proposition, we find that interrogatives are more likely to make use of futurizing morphology than declaratives. However, when using interrogatives speakers can also choose to ostensibly demonstrate a lower degree of epistemic authority than necessary, creating rhetorical effects. By using a bottomup classification of our data regarding their potential to express modal meanings, we demonstrate that (a) Spanish speakers conventionally exploit the combination of futurizing morphology and interrogative constructions for rhetorical effects as in (2), and (b) that this conventionalization affects the synthetic future (1b) to a greater degree than the periphrastic future (1a). Finally, we document substantial dialectal variation in the use of futurizing morphology.

\section{Futurity and evidentiality in the Spanish future tense}

Unlike Germanic languages, Spanish has both an inflectional future form -the synthetic future (SF)- as in Hablarán con él mañana 'They will speak to him tomorrow', and a periphrastic future construction (PF) <ir a 'go to' + infinitive>, as in Te lo voy a mandar mañana 'I'll send it to you tomorrow', which have developed different functional and frequency profiles. The literature on Spanish future forms points out that both forms have evolved to express diverse types of modal and evidential meanings (see Palmer 2001: 105, Ledgeway \& Maiden 2016, Marín Arrese 2017, among many others). However, the uses and values described in the literature are simply the effects of combining a basic abstract semantics with different contextual aspects (cf. Escandell-Vidal 2010: 29), and, consequently, there are yet neither comprehensive typologies that do justice to all the (newly evolved) meanings and uses of the SF and the PF, nor exhaustive descriptions of their formal features, including aspects of prosody and discourse structure. The field of study of Spanish future forms is highly complex because (i) there is tension between two paradigms (synthetic and periphrastic future forms), and (ii) the forms have numerous semantic-pragmatic values, which (iii) have a different distribution across varieties of the language, i.e. there is variable productivity -in terms of types and tokens-across varieties.

The Spanish SF and PF have a wide range of possible interpretations. In the case of the SF, there is no systematic correlation between future tense and future time reference. It is prototypically used for provisional or less certain statements about the future, for promises or predictions, especially longterm ones, for concessions, and for commands, threats, or warnings. The PF, in contrast, mainly expresses posterity -either relative to the moment of speech or to a previous event-, and it often conveys imminence. In combination with a past tense it can refer to the unexpected realization of an 
event -with 'focal value'-, as in (3), and it can also have a scalar value with 'culminative aspect', as in (4) (terms from Garachana 2019).

(3)

$\begin{array}{lllllll}\text { Fue } & \boldsymbol{a} & \text { llov-er el día de mi boda. } \\ \text { go.IND.PRS.3SG to } & \text { rain-INF the day of } & \text { my wedding }\end{array}$

'It had to rain on my wedding day.'

(4)

$\begin{array}{llllllll}\text { Tanto } & \text { nad-ar } & \text { para } & \text { ir } & \text { a } & \text { mor-ir en la orilla } \\ \text { so.much } & \text { swim-INF } & \text { in.order.to } & \text { go.INF } & \text { to } & \text { die-INF in } & \text { the shore }\end{array}$

'To come so far only to fall at the last hurdle' (lit. 'To swim so much only to die on the shore')

Interestingly, the use of the SF expressing future time reference is gradually declining in spoken Spanish, more so in Latin American varieties than in Spain (Butt \& Benjamin 2011: 319; Moreno de Alba 1993; Sedano 2006; Escandell-Vidal 2010: 12). It is often replaced by the PF, which has become the most common way to express futurity in all varieties of the language. This functional redistribution is the outcome of a gradual process of change. Aaron (2006) found that the PF has been making inroads into erstwhile SF territory from the 17th century on, leading to a shift in the division of labor: the SF is used increasingly with epistemic modal meaning (Palmer 2001, Nuyts 2001: 21) (e.g. ¿¿Dónde estará María ahora? 'Where might María be now?'), while the PF acquired the status of default future marker in the 20th century (Aaron 2006; Company Company \& Cuétara Priede 2014: 274).

Non-temporal uses of the Spanish future have received quite some attention in the literature (Gennari 2000, Matte Bon 2006, Rivero 2014, among others). Escandell-Vidal (2010, 2014, 2018: 111) offers a unitary account of all the (temporal and non-temporal) meanings of the SF in terms of evidentiality, arguing that the SF indicates conjectural evidence: the speaker presents a state-of-affairs for which the mode of knowing is intuitive inference, as in (5), as opposed to direct evidence. The SF is said to encode a procedural instruction to interpret the propositional content as the result of a mental process by the speaker. The same applies for uses of the SF that express 'necessity' (see example 6). Escandell-Vidal argues that the meaning of examples such as (6) is derived from inference, in the sense that it represents a conjecture about the future: it implicates that once the hearer makes an effort, she or he should be able to understand the urgency of the situation. As for the PF, no comprehensive account exists, and not enough attention has gone to the study of more recently developed uses.

$\begin{array}{lllll}\text { (5) Luz no vino } & a & \text { trabaj-ar. } & \text { Est-a-r-á } & \text { enferma. } \\ \text { Luz no come.IND.PST.PFV.3SG } & \text { to } & \text { work-INF } & \text { be-TH-FUT-3sG } & \text { sick }\end{array}$

'Luz didn't come to work. She must be sick' 


Comprend-e-r-ás la urgencia de la situación.
understand-TH-FUT-2SG the urgency of the situation

'You need to understand the urgency of the situation.'

In this paper we aim at illustrating the impact of sentence type on the meaning of the Spanish future, a topic which has likewise not been explored in previous analyses. In (7) below, we illustrate the existence of systematic correlations between these two variables. We already know that the use of the SF in declaratives sometimes leads to an evidential meaning that can be translated into English using the modal verb must (see examples 1 and 7a). Similarly, SF forms in polar interrogatives may give rise to an evidential meaning; in (7b) the speaker proposes that Luz did not go because she was ill. ${ }^{1}$ The difference between (7a) and (7b) appears to reside in the degree to which the speaker is committed to the truth of this hypothesis, and this is of course precisely why (7b) is framed as a question. Essentially, in (7b) Bea asks Alba to confirm the truth of the hypothesis she has derived from Alba's utterance via inference. Due the lower degree of epistemic commitment by Bea to the truth of the proposition, this meaning is best translated into English with the modal could.

The use of negation (7c) appears to further modify the meaning of the SF form in polar interrogatives, indicating an even lower degree of epistemic commitment by the speaker. Although as in (7b), Bea asks a confirmation question in (7c), the request has a strong intersubjective dimension. Bea wants Alba to reach the same inference on the basis of the available evidence and consequently align with Bea's perspective on this state of affairs. Bea tries to achieve this aim by ostensibly lowering her degree of epistemic commitment. Essentially, Bea puts forth that because Alba has not shown that she has reached the same inference as Bea, Bea is considering being mistaken about a state of affairs that actually seems quite evident to her. Although the use of a future-inflected declarative (7a) or polar interrogative (7b) would also be compatible with such a discourse-pragmatic context, the use of the negated future-inflected interrogative in (7c) appears to be especially polite. This is due to the conventionalized indirectness of the question.
Alba: Luz
no vino
$a$
trabaj-ar.
Luz not
come.IND.PST.PFV.3SG to
work-INF
'Luz hasn't come to work.'

\footnotetext{
${ }^{1}$ In the examples in (7b-e), the future forms could be easily be replaced with the conditional (e.g., est-a-ría 'beTH-COND.3sG), the only difference meaning that the temporal reference would be transposed to the past, as was also confirmed by our native speaker informants. This supports our view that ( $7 \mathrm{~b}-\mathrm{e})$ express modal meanings.
} 

a) Bea: Est-a-r-á enferma.
be-TH-FUT-3SG ill
'She must be ill.'
b) Bea: ¿Est-a-r-á enferma?
be-TH-FUT-3SG ill
'Could she be ill?'
c) Bea: ¿No est-a-r-á enferma?
not be-TH-FUT-3SG ill
'Could it be that she is ill?'
d) Bea: ¿Dónde est-a-r-á ahora?
where be-TH-FUT-3SG now
'Where might she be now?'
e) Bea: ¿Qué sab-rá-s tú de puntualidad?
what know-FUT-2SG you about punctuality
'What would you know about punctuality?'

Because $w h$-interrogatives are formally incomplete, i.e. explicitly signal that the speaker cannot establish the reference of one element of the sentence (Fiengo 2007: 44-80), they cannot be used to assert a hypothesis established by the speaker or ask for confirmation of this hypothesis. As a result, the use of future forms affects $w h$-interrogatives in a fundamentally different manner than it affects polar interrogatives. In (7d), the use of the SF does not seem to imply a lower epistemic commitment by the speaker. Compared to the use of the present tense, it rather appears to suggest that the hearer does not possess relevant information about Luz's whereabouts, too. The use of the future form thus balances out the epistemic cline between speaker and hearer instead of emphasizing the speaker's lack of knowledge.

In some wh-interrogatives the use of the future form can actually lead to a change in speech act type. In (7e), the futurized wh-interrogative is not used to negotiate the information status of speaker and hearer, but rather to challenge the grounds for Alba's assertion. The interrogative communicates that since Alba does not show up to work regularly herself, she has no right to complain about Luz's absence or even bring up the topic. As described in previous studies on interactional challenges (see Koshik 2003; Other \& Author 2018; Author 2019), the $w h$-interrogative essentially pretends to ask for a fact that is known to all interlocutors ('Alba cannot know anything about punctuality because she is never punctual herself'), which serves as the basis for a refutation of the relevance of the interlocutor's previous remark. The use of the future form is then motivated by this inference; the example could be 
paraphrased as 'You should be able to infer from the fact that you know nothing about punctuality that you should not comment on Luz's lack of punctuality'. As in example (7c), this rhetorical effect arises from Bea's ostensibly lowering the degree of epistemic commitment, which likewise amounts to a type of conventionalized indirectness.

Finally, it appears that the probability for future forms to lead to an evidential interpretation is higher in indirect information requests, i.e. embedded interrogatives (see 8 and 9). This is due to the fact that by embedding what is formally a declarative under a matrix predicate with the meaning 'I do not know', the speaker explicitly signals her lack of knowledge regarding the state of affairs expressed in the subordinated clause, tipping the epistemic cline.

(8) Alba: $\mathrm{He}$

\begin{tabular}{llllll}
\multicolumn{2}{l}{ have.IND.PRS.1SG } & buy-TH-PTCP spinach & for & DET.DEF.M.SG \\
almuerzo. & No & sé & si & te & gust-a-rá. \\
lunch & not & know.IND.PRS.1SG & if & you & like-TH-FUT-3SG
\end{tabular}

'I have bought spinach for lunch. I don't know whether you like it.'

(9) Alba: Voy a prepar-ar el almuerzo.

go.IND.PRS.1SG to prepare-INF DET.DEF.M.SG lunch

No sé qué te gust-a-rá.

not know.IND.PRS.1SG what you like-TH-FUT-3SG

'I am going to prepare lunch. I don't know what you like to eat.'

In summary, the considerations from the discussions of the examples in (7)-(9) lead us to assume that in Spanish, sentence type and negation have an important influence on the meaning of the future construction and consequently, the variation between the SF and the PF. This interaction can be framed in terms of the degree of epistemic commitment by the speaker over the proposition and especially the conventionalized rhetorical effects that can be achieved by ostensibly lowering the degree of epistemic commitment.

\section{Data}

In order to investigate the influence of sentence type on the use of future forms and the relevance of the parameter of epistemic commitment, we used two corpora of spoken Spanish in Madrid (Spain), Buenos Aires (Argentina) and Santiago de Chile (Chile): the C-ORAL ROM (Cresti \& Moneglia 2005) and the COLA (Jørgensen \& Eguía Padilla 2017). While the C-ORAL ROM only represents spoken 
Madrilenian Spanish from the time around 2005, the COLA represents contemporary spoken Spanish in all three Spanish dialects. The two corpora also differ in terms of the representation of diaphasic differences (whereas the C-ORAL ROM contains texts from various situations, including formal settings such as TV debates, the COLA is restricted to highly informal conversations), the age of the participants (the C-ORAL ROM contains speech from all age groups, whereas the COLA is restricted to the language of 13-19 year old adolescents) and size (whereas the C-ORAL ROM contains about 300,000 words, the COLA contains about 700,000 words). In order to maintain comparability between the two corpora, we eliminated those texts from the C-ORAL ROM that could be described as dissimilar to the COLA data. Consequently, we reduced the C-ORAL ROM data to familiar and public conversations, dialogues and monologues (C-ORAL tags efamcv, efamdl, efammn, epubcv, epubdl and epubmn). The characteristics of the two corpora are described in Table 1 below.

Table 1. Summary of the two corpora employed for this study.

\begin{tabular}{|l|l|l|}
\hline & C-ORAL ROM (selection) & COLA \\
\hline Dialect(s) & Madrilenian Spanish & Madrilenian Spanish \\
& & Santiaguino Spanish \\
\hline Size & $\sim 300,000$ words & $\sim 500,000$ words (Madrilenian) \\
& $\begin{array}{l}\text { Familiar and public } \\
\text { conversations, dialogues and } \\
\text { monologues }\end{array}$ & $\sim 150,000$ words (Santiaguino) \\
\hline Speech settings & All age groups & $\begin{array}{l}\text { Adolescents aged between } 13 \\
\text { and 19 years old }\end{array}$ \\
\hline Participants & around 2005 & $2002-2012$ \\
\hline Dating of recordings & &
\end{tabular}

In a first step, we extracted all occurrences of the PF and SF from the C-ORAL ROM and the COLA, using regular expressions. Due to the bigger size of the Madrilenian section of the COLA corpus $(\sim 500,000$ 
words), we obtained a disproportionate number of future-inflected sentences from this dataset $(n=3,738)$, which is why we selected a random sample of $n=600$ tokens. We then proceeded to manually eliminate false positives from these data. After this elimination procedure, we arrived at a final total of $n=2,749$ tokens. Table 2 details the distribution of these tokens. It demonstrates that the three dialects differ in terms of the relative usage frequency of synthetic future morphology; in both Madrilenian Spanish corpora, the synthetic future is used more frequently, whereas in Southern American Spanish, its relative usage frequency is below ten percent. There is also statistically significant difference in the distributions for the Madrilenian Spanish samples from the C-ORAL and the COLA $\left(\chi^{2}(1)=13.25, p<.001\right)$. This difference might be due to either sampling differences, in particular in register (the COLA data represents spoken Spanish in a much more relaxed and informal setting) or possibly language change, as the speakers are generally younger in the COLA.

Table 2. Usage frequencies of SF and PF in the C-ORAL and COLA corpus

\begin{tabular}{|l|l|l|l|l|}
\hline & C-ORAL & COLA & \multicolumn{2}{|l|}{} \\
\hline & Madrid & Madrid & Buenos Aires & Santiago \\
\hline $\boldsymbol{n}$ Periphrastic future & 702 & 427 & 462 & 593 \\
\hline $\boldsymbol{n}$ Synthetic future & 335 & 131 & 46 & 56 \\
\hline \% Synthetic future & 32.3 & 23.5 & 9.1 & 8.6 \\
\hline
\end{tabular}

\section{Evidential readings in future-inflected interrogatives}

In this section, we describe three contextual predictors that allow distinguishing temporal, evidential and challenge uses of future forms in Spanish, on the basis of an interactional analysis of selected examples. Consider the negated future-inflected polar interrogative in example (10) below, which expresses an evidential meaning.

(10) el cine (Informal conversation, epubcv02, C-ORAL ROM)

$\begin{array}{llllll}01 \text { FER: } & \text { ¿H-as } & \text { i-do } & a & \text { v-er Torrente } & \text { ya? } \\ & \text { have-IND.PRS.2SG } & \text { go-PCTP } & \text { to } & \text { see-INF Torrente } & \text { already } \\ & \text { 'Did you go to watch Torrente already?' } & & \end{array}$




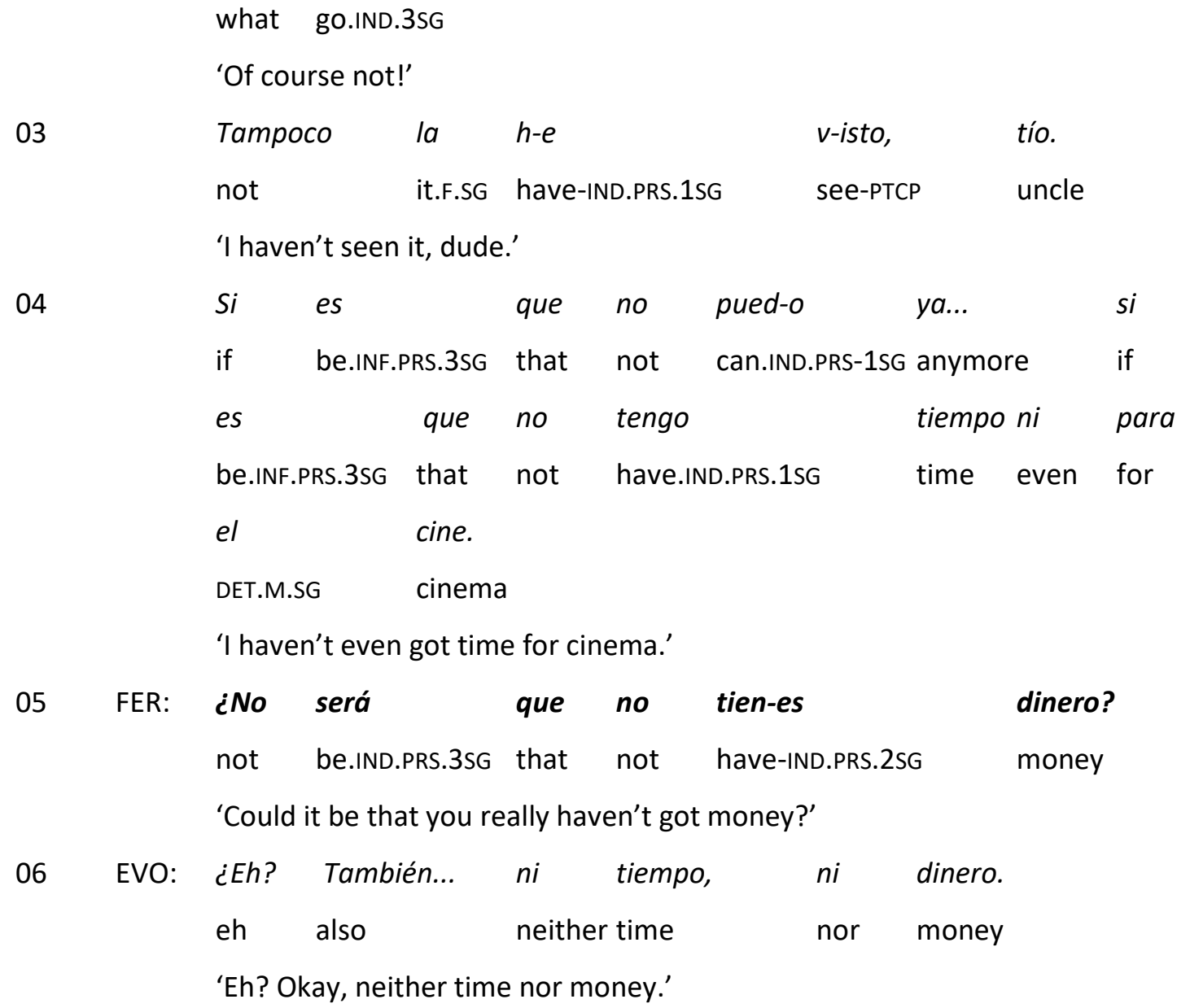

FER asks EVO whether he has already watched the new movie 'Torrente' (I. 1). EVO responds negatively to this question (I. 2), claiming that he just does not have time anymore for such activities (I. 3-4). However, FER suspects that, actually, the problem may be that EVO does not have money. He asks EVO to confirm this inference (I. 5), and EVO, although slightly taken aback, does indeed confirm FER's suspicion (I. 6).

The description of example (10) has made clear that the evidential meaning of FER's future-inflected interrogative arises by virtue of an inference process, namely FER's assumption that EVO's real problem is money. This inference process can be modeled using the Question Under Discussion approach (see Author, this special issue for an introduction to QUD modelling), which yields the structure in (11). FER's interrogative expresses the QUD $Q_{2.1 .1}$, which is deduced by a complex inference process from the previous QUD $Q_{2}$. Effectively, FER asks EVO to confirm the validity of this inference process, implicating that EVO could have reached this inference himself. As hypothesized in Section 2, such uses of negated polar interrogatives ostensibly communicate an especially low epistemic commitment by speaker and are can therefore be considered polite. If the speaker were to use a 
declarative (no tendrás dinero) in this example, the speaker would commit to a greater degree to the truth of a proposition that is conflictual in the sense that it contradicts EVO's previous utterance (i.e. FER proposes that EVO's problem is not time, but money). Consequently, FER's use of the negated polar interrogative serves to attenuate the face-threatening force of his assumption.

(11) QUD structure for example (10), using English translations FER:

$\mathrm{Q}_{1}: \quad$ Did you go to watch the movie Torrente already?

EVO:

$>A_{1}: \quad$ Of course not! I haven't seen it, dude. I

$>\mathrm{Q}_{2}: \quad$ :Why did you not watch Torrente?

> $A_{2}$ : I cannot [do this kind of activity] anymore. I haven't even got time for cinema.'

FER:

$>Q_{2.1} \quad$ \{Is there another reason why you cannot go to the cinema?\}

$\gg Q_{2.1 .1} \quad$ Could it be that you don't have money to go to the movies?

FER:

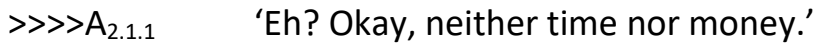

Finally, we observe at least three formal contextual indicators of the evidential reading of the future form in example (10). First, the verb is conjugated in third person, indicating that in comparison to first person morphology, the speaker does not have direct evidence for the truth of the proposition. Second, the predicate (here ser 'to be') expresses a stative meaning, which is less prone to futurity readings. Third, there is no temporal adverb or clause present which could indicate a futurity reading.

The situation is more complex in the case of $w h$-interrogatives, which can express not only temporal and evidential readings, but also interactional challenges. In example (12) we give an example of a whinterrogative with an evidential reading. DAN and GUS have been talking about dubbed movies and agree that much of the original is lost in the translation, which is why DAN argues that it is a shame. In I. 1 he repeats this assessment and then wonders, using a future form, who might be responsible for this practice (I. 2). He then goes on to provide an answer himself in a morphosyntactic format that emphasizes his lack of knowledge (I. 3); in particular, he uses the overt subject pronoun yo to establish a contrast. This contrast invites GUS' opinion on the topic and GUS indeed takes up DAN's suggestion 
in I. 5-6. In this sense, the future-inflected $w h$-interrogative serves as a topic initiator, opening up a new QUD in discourse.

(12) doblaje (epubdl12, C-ORAL ROM)

01 DAN: Hhh... una pena.

hhh det.INDF.F.SG shame

'Hhh, a shame.'

02

¿Quién habrá

who have.IND.FUT.3sG

impues-to la

costumbre del

doblaje?

dubbing

'Who do you think was it that established the practice of dubbing movies?'

03

Yo lo relacion-o con la censura.

I it relate-IND.PRS.1SG with DET.DEF.F.SG censorship

'Personally, I think it has something to do with censorship.'

$04 \quad[\ldots]$

05 GUS: Que sí...

that yes

'Well, yes.'

06

Que a partirde la
that from época franquista
se empez-ó.
REFL begin-PST.PFV.3SG

Example (12) is similar to example (10) in several ways, reflecting its evidential meaning. First, it resembles the discourse-pragmatic constellation in example (10) in that the proposition of the interrogative is based on an inference drawn by the speaker ('if movies are usually dubbed nowadays, at some point someone must have started doing this'). Just like the polar interrogative in (10), the whinterrogative in (12) marks the proposition of a question as based on this inference, with the difference that it does so in a roundabout way: by asking about a fact that is logically entailed by this inference ('who was the person who started dubbing movies?'), the speaker actually enables a discussion not only about his specific question, but also about the question proposition. The effect of this procedure is that it invites an open speculation about this topic. For instance, it would have been also been 
pragmatically adequate, and maybe even invited for GUS in this context, to challenge the presupposition that there was someone specific who started the practice of dubbing.

Second, note that in example (12) all contextual predictors identified as relevant for an evidential reading in example (10) are present again: third person morphology, a stative predicate (after all, the question can best be translated using a cleft interrogative such as 'Who was it that established the practice of dubbing movies?'), and no future-referring expressions (on the contrary, the use of the perfect construction expresses anteriority, thus excluding a temporal interpretation).

In (13) we give another example for the use of future-inflected wh-interrogative as an interactional challenge (see example 2 above). PIE and PAZ are talking about Raquel Mosquera, the wife of Pedro Juan Carrasco García, a famous Spanish boxer who died in 2001. PIE has just claimed that Mosquera received 50 million pesos for Carrasco García's death, which PAZ finds hard to believe. In I. 1, she consequently asks PIE for confirmation. PIE repeats his statement in I. 2. and in I. 3 backs it with information about his source. However, PAZ is still not convinced and asks PIE to confirm this latter statement (I. 4); PIE assents non-verbally in I. 5. In I. 6 PAZ finally uses a future-inflected whinterrogative to utter an interactional challenge; in particular, the question implies that she cannot imagine a world in which Mosquera would receive that much money for her husband's death.

(13) Mosquera (C-ORAL ROM, efamdl33)

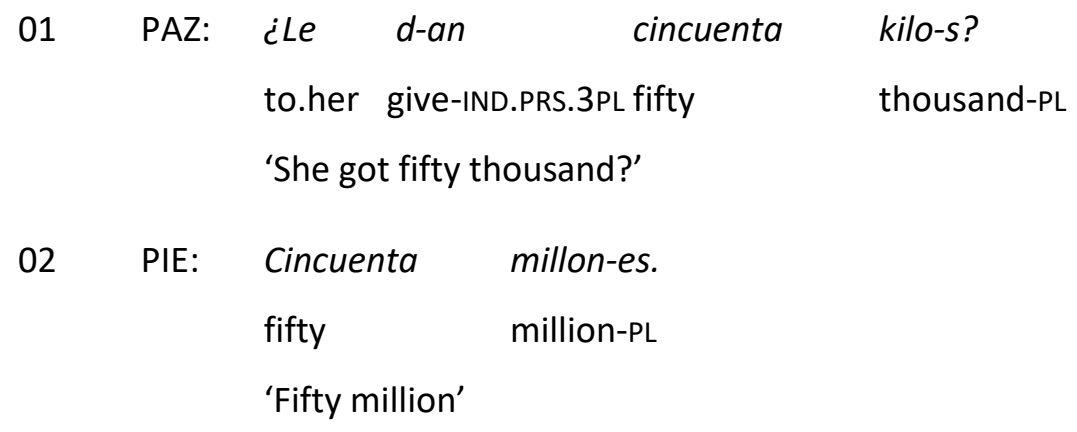

03
Que lo dij-eron
anoche.
that it say.IND.PST.PFV-3PL
yesterday.night
'They said so last night'

04 PAZ: ¿Sí?

yes

'Really?'

05 PIE: hhh (assents) 
'And how could they possibly give her fifty?'

In terms of the knowledge states of the interlocutors, examples (12) and (13) are very similar. As in (12), there is strong evidence for the truth of the presupposition of the question in (13) (in particular, PIE has explicitly mentioned that Mosquera will receive 50 million pesos). In both cases, the use of the future form conveys that the speaker does not expect the hearer to know the answer to the question. In example (13), PAZ assumes that PIE cannot really explain why Mosquera would have received that much money and she conveys that Mosquera surely did not get that much money. Again, this effect derives from the roundabout way of asking about a fact that is logically entailed by the proposition in the question: by asking how they could give Mosquera fifty million pesos, PAZ actually starts a discussion about whether they gave Mosquera fifty million pesos. Consequently, it is not surprising that example (12) and (13) are similar in terms of the contextual predictors that identify these meanings as evidential; as in example (12), PAZ's challenge in (13) is characterized by third person morphology and by the lack of future-referring expressions.

The difference between (12) and (13) resides in that in (13), the answer to the question of whether they gave Mosquera fifty million pesos should be evident because PIE already affirmed this fact previously. In other words, there is a contrast between the conversational implicature realized by the question ('there is no way Mosquera could have received fifty million pesos') and PIE's previous affirmation. It is this contrast that spawns the interactional challenge reading, whereas in (12), the absence of such a contrast leads to the interpretation that open speculation is invited. One notable difference involves the use of the conjunction $y$ 'and', which explicitly links the utterance to the preceding context and thus appears to emphasize the contrast between PIE's previous utterance and PAZ's belief. The use of pero 'but' seems to be equally possible here (see Other \& Author 2018).

The discussion of the examples in (10)-(13) has shown that while the use of future-inflected polar interrogatives and $w h$-interrogatives with an evidential meaning can be described in terms of the degree of epistemic commitment of the speaker to the truth of the proposition, this description does not do justice to the pragmatic functions expressed by such constructions in discourse. In particular, it appears that future-inflected polar interrogatives are efficient devices for introducing a hypothesis due their indirectness and consequently, politeness, and that speakers can use future-inflected whinterrogatives in order to invite open speculation about a topic and thus open up a new QUD, or to challenge a previous claim by the hearer. None of these functions can be characterized as information 
questions in a strict sense (i.e. a request to the hearer to update the speaker's personal ground with a piece of information that the speaker does not possess, whereas the hearer does). The question would then be whether these interpretations always arise as a function of the semantics of these futureinflected interrogatives combined with the contextual information, or whether the interrogative types have conventionalized these form-function associations. In other words, do these readings arise on the basis of conversational or conventional implicatures?

We believe that this question cannot be answered on the basis of a qualitative analysis alone. Rather, only a statistical analysis can show whether or not the interrogative types in (10)-(13) have conventionalized the actional meanings of 'politely proposing a possibly face-threatening hypothesis', 'inviting open speculation about a topic' and 'challenging a previous move by the hearer'. In particular, we would assume that if such form-function conventionalizations have taken place, evidential meanings are much more likely to arise for these interrogative types than for the other constructional types described in Section 2 (especially declaratives and non-negated polar interrogatives), reflecting the fact that these interrogatives are typically used to express the meanings described in this section.

Such conventionalization processes may also exploit a further formal indicator of the difference between temporal and evidential uses of future forms, namely the opposition between the PF and the SF. As was mentioned in Section 2, previous research indicates that the SF is much more likely to express evidential meanings than the PF. If this is the case and with the constructional types described in this section evidential meanings have led to the conventionalization of certain actional meaning, we might expect the use of the SF to be more likely for these form-function pairings. Such a finding would be indicative of a constructionalization process (Traugott \& Trousdale 2013), in that the semantic change (conventional use of these constructional types with the actional meanings) would coincide with a formal change (preferred use of the SF).

In summary, the discussion of the examples in (10-13), as well as example (7) in Section 2, lead us to formulate the three predictions in (14).

(14) P1 Since polar interrogatives typically involve a lower degree of epistemic commitment by the speaker towards the proposition than declaratives, future forms are more likely to express epistemic modal meanings with this sentence type.

P2 This "modalizing effect" of polar interrogatives is moderated by negation and indirectness, in that such interrogatives involving a future form display what could be interpreted as an even lower degree of epistemic commitment, leading to an even higher 
probability of an evidential interpretation. Since this indirectness entails a politeness effect, we expect negated and embedded future-inflected polar interrogatives to be even more likely to express epistemic modal meanings. Likewise, in wh-interrogatives, the use of future forms leads to discourse-managing interpretations (invite open speculation about a topic and challenge a previous utterance). Due to the relevance of such discourse-managing functions, we expect future-inflected $w h$-interrogatives to be especially likely to express epistemic modal meanings.

P3 In line with existing research on future forms in Spanish, we assume that the SF is specialized in the expression of modal meanings, whereas the PF typically expresses future tense. We also expect interactions between the SF/PF alternation and sentence type regarding the expression of evidential meanings, in that due to conventionalization processes, the SF is even likelier to trigger evidential meanings in negated polar interrogatives and $w h$ interrogatives.

\section{Quantitative analysis}

\subsection{Analytical approach}

As was shown in the qualitative analysis, future forms almost always allow for both a temporal and a modal reading. Consequently, although careful analysis using tools from interactional analysis allows us to propose with a high level of confidence that an example such as (10) above can be considered expressing an evidential meaning, such an analysis only takes into account the speaker meaning. There are always cases in which the hearer misinterprets the intended reading. Consequently, the fact that an evidential meaning is intended does not invalidate the tense-mood metonymy as such.

However, the qualitative analysis in Section 4 has also demonstrated that there are certain contextual cues for evidential readings. First, evidential readings are much less likely to arise when the verb is conjugated in first person than in second and third person, because the speaker usually has a higher degree of epistemic authority over her or his future actions than over the future actions of a different person (in line with Escandell-Vidal 2010: 30). Second, evidential readings are more likely to be intended when a stative predicate (most prominently, ser 'be') is expressed. The reason for this relationship is that due to their stativity, such predicates are more likely to be interpreted as referring the present than to the future. Third, an evidential interpretation becomes less likely in the presence of futurity-oriented adverbs (e.g., ahora 'now' or mañana 'tomorrow') or temporal clauses (e.g., cuando lleg-uen 'when arrive-SBJ.PRES.3PL'). 
Given that, as described above, in principle the meaning of the future constructions is always ambivalent, we refrained from coding speaker meanings in our data. Such a seemingly direct approach to the interpretation of the data is problematic because (a) even for native speakers of Spanish it is frequently impossible to be entirely certain about the speaker meaning and (b) such an approach entails the danger of circularity.

Instead, we adopted an indirect approach to the description of the preferred meanings of our $n=5,932$ tokens of SF and PF constructions. Thus, in order to arrive at an objective measurement of the potential for each of these contexts to support an evidential meaning, we established the variable EVIDENTIAL, which describes the likelihood for a given context to be interpreted as expressing an evidential meaning on the basis of the three objective and quantifiable criteria detailed above.

The variable EVIDENTIAL received four values, "Unlikely", "SomewhatLikely", "Likely", and "VeryLikely", on the basis of a simple weighting mechanism. Each token in our corpus received one point for each of the following criteria:

1. Second- or third-person morphology

2. Stative predicate used

3. Non-presence of a futurity-oriented adverb or temporal clause

This weighting mechanism thus first led to a variable with four values $(0,1,2,3)$. These values were distributed as follows: $n_{\text {Unlikely }}=120, n_{\text {Somewhatlikely }}=1,129, n_{\text {Likely }}=1,096, n_{\text {verylikely }}=404$. We manually coded 1,328 tokens of the data in terms of our intuitions regarding the functions of the future forms and found a reasonably high overlap between our intuitions and the variable EVIDENTIAL. Thus, 84 percent of the cases that received the level "Unlikely" in the EVIDENTIAL variable were classified as "temporal" in our manual coding, whereas only 45 percent of the cases that received the level "VeryLikely" in the EVIDENTIAL variable were classified as "temporal".

We used the variable EVIDENTIAL as dependent variable in a mixed-effects ordinal logistic regression model (Johnson \& Albert 2004; Agresti 2010), which thus effectively predicted the likelihood for a given context to express an evidential meaning on the basis of a number of distinct contextual criteria), listed in Table 3 below, that were chosen in agreement with the hypotheses described at the end of Section 4. Note that the variable SENTENCETYPE was operationalized such that it included a manual interaction between sentence type and negation, but only for polar interrogatives (level "IntPol.neg"). The use of a mixed-effects model allowed us to control for the influence of the specific conversation, nested in the specific dialect (DIALECT:FILE), which in turn represents the specific stylistic preferences of the 
language users in that conversation, as well as their dialect (see Gries 2015 for nested random effects structures). Likewise, we included a random effect PREDICATE, controlling for the specific predicate of the future form. The regression model was fitted in $\mathrm{R}$ using the clmm function from the ordinal package (Christensen 2019).

Table 3. Description of predictor variables (fixed and random effects) in the ordinal logistic regression model

\begin{tabular}{|c|c|c|c|}
\hline Variable & Variable type & Levels & Description \\
\hline \multirow[t]{7}{*}{ SENTENCETYPE } & \multirow[t]{7}{*}{ Fixed effect } & $\operatorname{Decl}(R L)$ & Declaratives \\
\hline & & Decl.tq & Tag questions \\
\hline & & IntPol & Polar interrogatives \\
\hline & & IntPol.neg & Negated polar interrogatives \\
\hline & & IntPol.emb & Embedded polar interrogatives \\
\hline & & IntWh & Wh-interrogatives \\
\hline & & IntWh.emb & Embedded $w h$-interrogatives \\
\hline \multirow[t]{2}{*}{ CONSTRUCTION } & \multirow[t]{2}{*}{ Fixed effect } & $\mathrm{PF}(\mathrm{RL})$ & Periphrastic future \\
\hline & & SF & Synthetic future \\
\hline \multirow[t]{3}{*}{ CONJUNCTIONTYPE } & \multirow[t]{3}{*}{ Fixed effect } & None & $\begin{array}{l}\text { No conjunction or low-frequency } \\
\text { conjunctions other than pero 'but' and } \\
y^{\text {'and' }}\end{array}$ \\
\hline & & Pero & Use of pero 'but' \\
\hline & & $Y$ & Use of $y$ 'and' \\
\hline PREDICATE & $\begin{array}{l}\text { Simple } \\
\text { random } \\
\text { effect }\end{array}$ & $\begin{array}{l}\text { aborrecer 'to hate', } \\
\text { abrir 'to open', } \\
\text { aburrir 'to bore', etc. }\end{array}$ & Predicate of the future form \\
\hline DIALECT:FILE & $\begin{array}{l}\text { Nested } \\
\text { random } \\
\text { effect }\end{array}$ & $\begin{array}{l}\text { (combination of the } \\
\text { levels of DIALECT and } \\
\text { FILE) }\end{array}$ & $\begin{array}{l}\text { Dialect, where Madrilenian }{ }_{1} \text { refers to } \\
\text { the C-ORAL ROM data and } \\
\text { Madrilenian }{ }_{2} \text { to the Madrilenian } \\
\text { section of the COLA data }\end{array}$ \\
\hline
\end{tabular}

On the basis of the findings from the qualitative analysis in Section 4, we assumed that SF constructions have become particularly specialized in the expression of modal-evidential meanings, which might lead to more strongly conventionalized associations between sentence type and construction in the 
expression of modal meanings. Consequently, we tested for an interaction effect between SENTENCETYPE and CONSTRUCTION, with the expectation that the influence of SENTENCETYPE is stronger for SF than PF constructions.

\subsection{Results}

Table 4 summarizes the results from the ordinal logistic regression model. Positive log odds (LO) indicate an increase in the dependent ordinally scaled dependent variable EVIDENTIAL in the context of the predictor, whereas negative LO indicate a decrease.

Table 4. Results from the ordinal logistic regression model. $L O=\log$ odds, $S E=$ standard error, $Z=z$ values, $\mathrm{P}=p$ values. Significance levels: $\mathrm{p}<.05=*, \mathrm{p}<.01^{* *}, \mathrm{p}<.001^{* * *}$.

\begin{tabular}{|c|c|c|c|c|c|c|}
\hline Variable & Level & LO & SE & $\mathbf{Z}$ & $\mathbf{P}$ & \\
\hline \multirow{2}{*}{ CONSTRUCTION } & $P F(R L)$ & -- & -- & -- & -- & \\
\hline & SF & 0.56 & 0.14 & 3.96 & $<001$ & $* * *$ \\
\hline \multirow{7}{*}{ SENTENCETYPE } & $\operatorname{Decl}(\mathrm{RL})$ & -- & -- & -- & -- & \\
\hline & Decl.tq & 0.80 & 0.37 & 2.16 & $<.05$ & $*$ \\
\hline & IntPol & 1.21 & 0.20 & 6.18 & $<.001$ & $* * *$ \\
\hline & IntPol.emb & 0.62 & 0.50 & 1.25 & $>.05$ & \\
\hline & IntPolNeg & 1.70 & 0.50 & 3.40 & $<.001$ & $* * *$ \\
\hline & IntWh & 0.97 & 0.17 & 5.64 & $<.001$ & $* * *$ \\
\hline & IntWh.emb & 0.16 & 0.40 & 0.39 & $>0.5$ & \\
\hline \multirow{3}{*}{ CONJUNCTIONTYPE } & None (RL) & -- & -- & -- & -- & \\
\hline & Pero & 1.03 & 0.32 & 3.27 & $<.01$ & $* *$ \\
\hline & $Y$ & 0.26 & 0.21 & 1.26 & $>0.5$ & \\
\hline \multirow{6}{*}{ CONSTRUCTION : SENTENCETYPE } & SF : Decl.tq & 0.21 & 0.65 & 0.33 & $>0.5$ & \\
\hline & SF : IntPol & 0.11 & 0.62 & 0.18 & $>0.5$ & \\
\hline & SF : IntPol.emb & -0.18 & 0.72 & -0.26 & $>0.5$ & \\
\hline & SF : IntPol.neg & 0.16 & 0.96 & 0.16 & $>0.5$ & \\
\hline & SF : IntWh & 1.73 & 0.83 & 2.09 & $<.05$ & $*$ \\
\hline & SF : IntWh.emb & -0.05 & 0.66 & -0.08 & $>0.5$ & \\
\hline
\end{tabular}

The regression analysis found statistically significant effects for all main effects. First, according to the regression model, SF forms are significantly more likely to receive a higher value on the dependent variable EVIDENTIAL than PF forms. 
Second, compared to the reference level "Decl" (declarative sentences), a higher value on the dependent variable EVIDENTIAL is more likely for tag questions. It is even more likely for polar interrogatives. This effect is moderated by negation, in that negated polar interrogatives show the highest likelihood for a high value on the dependent variable EVIDENTIAL. Finally, the analysis found a higher value on the dependent variable EVIDENTIAL to be more likely for non-embedded whinterrogatives than declaratives. No statistically significant effects were found for the difference between declaratives and embedded polar and wh-interrogatives.

Third, the analysis found a statistically significant correlation between the dependent variable and the predictor variable CONJUNCTIONTYPE, in that in comparison to utterances that do not involve the use of the conjunctions pero 'but' and $y$ 'and', utterances introduced with the conjunction pero are more likely to score high on the dependent variable EVIDENTIAL. No such effect was found for $y$.

Finally, the analysis found the interaction between CONSTRUCTION and SENTENCETYPE to reach statistical significance. We visualize the interaction effect between CONSTRUCTION and SENTENCETYPE in Figure 1 below. The figure clearly demonstrates that, in comparison to declaratives, $w h$-interrogatives are even more likely to score higher on the dependent variable EVIDENTIAL in SF forms than in PF forms; in fact, more than 95 percent of all $w h$-interrogatives involving a SF are predicted to have a likely or very likely evidential meaning.

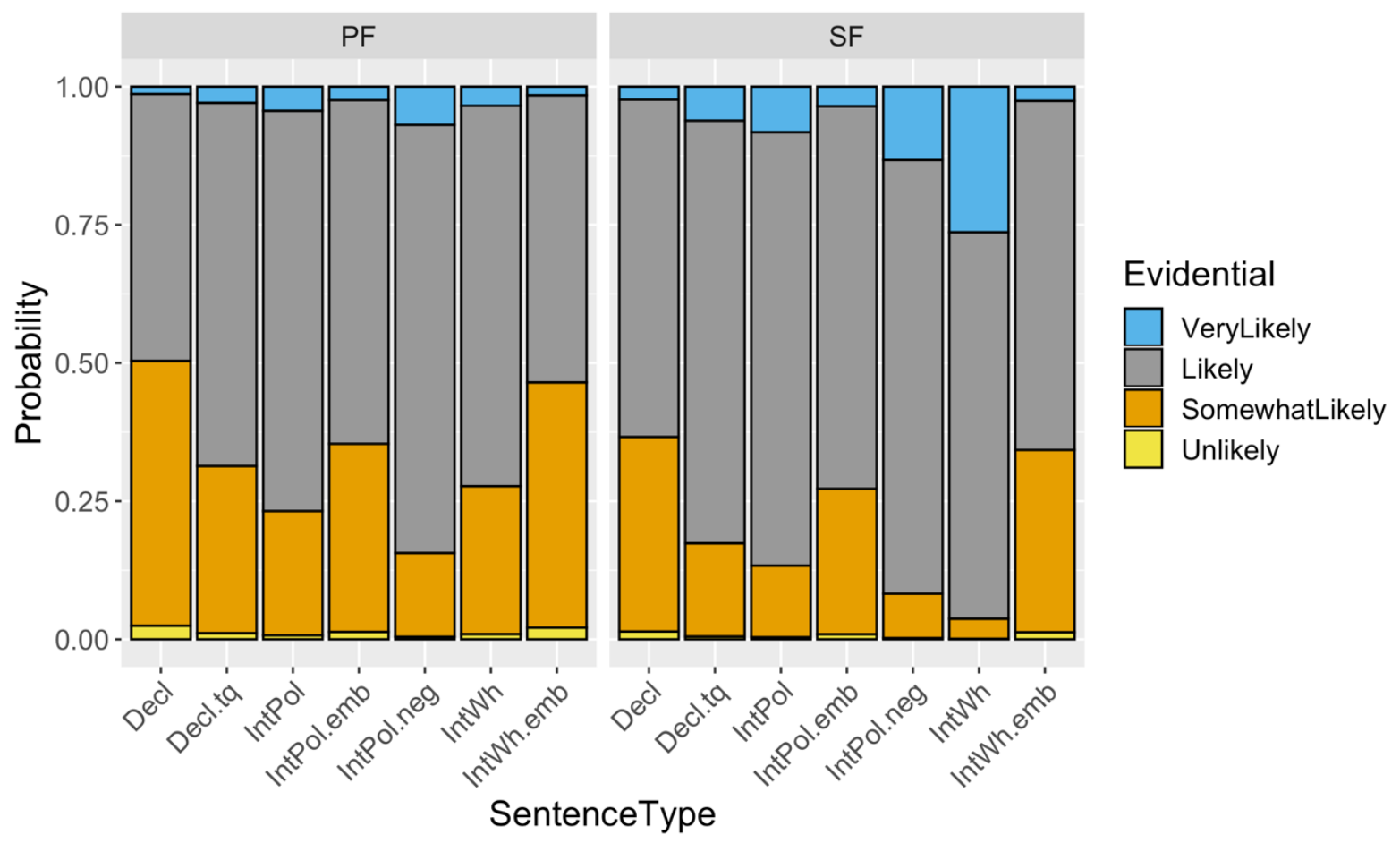


Figure 1. Effect plot of the interaction between CONSTRUCTION and SENTENCETYPE in the ordinal logistic regression model (dependent variable EVIDENTIAL). See Table 3 for an explanation of the abbreviations.

\subsection{Discussion}

The results from the ordinal logistic regression model confirm the predictions with respect to the influence of sentence type on the function of future forms proposed at the end of Section 4. First, irrespective of the constructional type (PF vs. SF), the use of a future form in a taq question and especially a polar interrogative is more likely to lead to an evidential interpretation than in a declarative (P1). This effect is even stronger in negated polar interrogatives and $w h$-interrogatives than in declaratives (P2). Finally, the model did find evidence for the assumption that for one constructional type, the influence of sentence type on the likelihood of evidential interpretations is moderated by the opposition between PF and SF: evidential readings are likeliest for wh-interrogatives inflected for the SF.

These findings confirm our hypothesis that these sentence types form a cline in terms of the degree of epistemic commitment of the speaker towards the truth of the proposition. We model this cline in (15), where positions to the left indicate a relatively high degree of epistemic commitment and positions to the right indicate a relatively low degree of epistemic commitment. The lower the degree of epistemic commitment typically associated with a sentence type, the higher the likelihood for a future form in such a context to express an evidential reading. Note however that the analysis did not find evidence for the influence of even finer-scaled distinctions on the basis of the embeddedness parameter.

$$
\text { Declaratives }>\text { Tag questions }>\text { Polar interrogatives }>\text { Negated polar interrogatives }
$$

Wh-interrogatives

Likewise, the model supports the hypothesis, formulated in Section 4, of a conventionalization of certain actional meanings ('politely proposing a possibly face-threatening hypothesis', 'inviting open speculation about a topic' and 'challenging a previous move by the hearer') for negated polar interrogatives and wh-interrogatives. As was expected on the basis of the results from previous studies, the analysis demonstrated that the use of a SF is more likely to lead to an evidential interpretation than the use of the PF. However, this effect is even stronger in the context of a whinterrogative, which indicates a constructionalization process in the terms proposed by Traugott \& Trousdale (2013); SF-inflected wh-interrogatives have conventionalized the actional meanings of 'inviting open speculation about a topic' and 'challenging a previous move by the hearer'. While these 
meanings were shown in Section 4 to be essentially evidential meanings, the conventionalization process indicates that the use of a SF-inflected wh-interrogative frequently no longer indicates a conversational but a conventional implicature. In other words, the meaning of these constructions is no longer necessarily derived from the combination of their context-invariant meaning and the meaning potential derived from the context, but is conventionally associated to these forms.

\section{Summary and outlook}

In this paper we looked at the use of SF and PF constructions in corpora of spoken Spanish from three varieties of the language, namely Madrilenian Spanish, Porteño Spanish and Santiaguino Spanish, to inquire into the relationship between futurizing morphology and sentence type. We departed from a qualitative analysis of the data, which showed that there is a functional redistribution between SF and PF constructions, being the PF the most common way to express futurity in all three varieties. In addition, we observed that futurizing morphology can lead to a series of rhetorical effects, as discussed in Section 2. Moreover, we observed a dialectal difference in that the SF is used more frequently in both Madrilenian corpus than in the South American ones.

In order to problematize the influence of sentence type in the meaning of the Spanish 'future' forms, we looked at the systematic correlations between the two, and found that it is possible to order the different sentence types in a cline according to whether they express a relatively higher or lower degree of epistemic commitment of the speaker to the truth of the proposition. Other factors affecting the ordering in such a cline are the presence of negation and conventional indirectness.

To differentiate between temporal, evidential and challenge uses of future forms in our data, we proposed three contextual predictors of an evidential reading: (a) the verb is conjugated in the third person, (b) the predicate expresses a stative predicate, and (c) there is no adverb or clause indicating a futurity reading. We showed that, although these predictors work very well in most contexts, for certain sentence types such as $w h$-interrogatives and polar interrogatives, the situation is more complex, given that these constructions can have specific pragmatic functions in discourse which cannot be characterized as information or confirmation questions in a strict sense.

In order to test the whether the interrogative types have conventionalized certain form-function associations, we proposed a statistical analysis in which we established the dependent variable EVIDENTIAL -in a mixed-effects ordinal logistic regression model- to signal the likelihood of a context to 
be interpreted as expressing evidential meaning, on the basis of distinct contextual criteria. The model found significant effects for all main effects, confirming that (a) SF forms are significantly more prone to be used in modalizing contexts than PF forms, (b) a higher value on the dependent variable EVIDENTIAL is more likely for tag questions, polar interrogatives and non-embedded $w h$-interrogatives than for declaratives, (c) a significant correlation exists between the dependent variable and the predictor variable CONJUNCTIONTYPE, and that d) the interaction between CONSTRUCTION and SENTENCETYPE reaches statistical significance. These findings confirmed our hypothesis and corroborated that the observed effects are indicative of a constructionalization process, which show a conventionalization of specific actional meanings for wh-interrogatives and negated polar interrogatives with futurizing morphology in general, and even more so with the SF.

Finally, in future studies we would also like to cover the most recent innovations, which have not been documented in our corpus data, such as the evidential use of the PF in semi-lexicalized clauses such as "Pues va a ser que no estamos locas" 'Surely (lit. it goes to be that) we are not crazy', whose intersubjective evidential meaning is 'surely' (cf. Downing 2001), 'I -and you-see' cannot be fitted very well into the abstract meaning of the speaker invoking conjectural evidence. Also, the pragmatic difference between the SF and PF minimal pair of wh-interrogatives such as "¿Qué sabrás vos de música? 'What would (lit. will) you know about music' and ¿Qué vas a saber vos de música?" 'What would you (lit. do you go to) know about music' is yet to be explained.

\section{References}

Aaron, Jessica. 2006. Variation and change in Spanish future temporal expression. Albuquerque: Albuquerque $\mathrm{PhD}$ thesis.

Agresti, Alan. 2010. Analysis of Ordinal Categorical Data. 2nd edition. Malden, MA: Wiley.

Author. 2019.

Butt, John \& Carmen Benjamin. 2011. A New Reference Grammar of Modern Spanish. 5th edition. Arnold: London.

Campos, Héctor, Elena Herburger, Alfonso Morales-Front \& Thomas J. Walsh (eds.). 2000. Hispanic Linguistics at the Turn of the Millennium. Sommerville: Cascadilla Press.

Christensen, Rune H. B. 2019. Ordinal-Regression Models for Ordinal Data. R package version 2019.12-10. https://CRAN.R-project.org/package=ordinal. Last access 23 June 2020. 
Company Company, Concepción \& Javier Cuétara Priede. 2014. Manual de Gramática Histórica. México, D.F.: Universidad Nacional Autónoma de México.

Cresti, Emanuela \& Massimo Moneglia. 2005. C-ORAL-ROM. Integrated reference corpora for spoken Romance languages. Amsterdam: Benjamins.

De Brabanter, Philippe, Mikhail Kissine \& Saghie Sharifzadeh (eds.). 2014. Future tense vs. future time: an introduction. Oxford: Oxford University Press

De Ruiter, Jan P. (ed.). 2012. Questions: formal, functional, and interactional perspectives. Cambridge: Cambridge University Press.

Downing, Angela. 2001. "Surely you knew!" Surely as a marker of evidentiality and stance. Functions of Language 8(2). 251-282.

Enfield, Nick J., Penelope Brown \& Jan P. de Ruiter. 2012. Epistemic dimensions of polar questions: sentence- final particles in comparative perspective. In Jan P. de Ruiter (ed.), 193-221.

Escandell-Vidal, María V. 2010. Futuro y evidencialidad. Anuario de Lingüística Hispánica 26. 9-34.

Escandell-Vidal, María V. 2014. Evidential futures: the case of Spanish. In: Philippe de Brabanter, Mikhail Kissine \& Saghie Sharifzadeh (eds.), 219-246.

Escandell-Vidal, María V. 2018. Evidential commitment and feature mismatch in Spanish estar constructions. Journal of Pragmatics 128. 102-115.

Fiengo, Robert. 2007. Asking Questions: Using Meaningful Structures to Imply Ignorance. Oxford: Oxford University Press.

Garachana, Mar. 2019. De cuando ir $a+$ infinitivo no se dirige al futuro. Construcciones gramaticales de pasado, sentido completivo y focalizador. Una aproximación desde la Gramática de Construcciones. Revista Española de Lingüística 49(1). 119-146.

Gennari, Silvia. 2000. Semantics and pragmatics of future tenses in Spanish. In Héctor Campos, Elena Herburger, Alfonso Morales-Front \& Thomas J. Walsh (eds.), 264-281.

Gries, Stefan Th. 2005. Syntactic priming: a corpus-based approach. Journal of Psycholinguistic Research 34(4). 365-399.

Heritage, John. 2012. Epistemics in Action: Action Formation and Territories of Knowledge. Research on language and social interaction 45(1). 1-29.

Johnson, Valen E. \& James H. Albert. 2004. Ordinal regression models. In David Kaplan (ed.), 151-174. 
Jørgensen, Annette Myre \& Esperanza Eguía Padilla. 2017. Proyecto COLA. Corpus Oral de Languaje Adolescente. http://www.colam.org/. Last access 21 December 2017.

Kaplan, David (ed.). 2004. The SAGE Handbook of Quantitative Methodology for the Social Sciences. Thousand Oaks: SAGE.

Koshik, Irene. 2003. Wh-questions used as challenges. Discourse Studies 5. 51-77.

Ledgeway, Adam \& Martin Maiden. 2016. The Oxford Guide to the Romance Languages. Oxford: Oxford University Press.

Marín Arrese, Juana I. 2017. Multifunctionality of evidential expressions in discourse domains and genres: Evidence from cross-linguistic case studies. In Juana I. Marín Arrese, Gerda Haßler \& Marta Carretero (eds.), 195-224.

Marín Arrese, Juana I., Gerda Haßler \& Marta Carretero (eds.). 2017. Evidentiality revisited. Cognitive grammar, functional and discourse-pragmatic perspectives. Amsterdam, Philadelphia: Benjamins.

Matte Bon, Francisco. 2006. Maneras de hablar del futuro en español entre gramática y pragmática. Futuro, ir a + infinitivo y presente de indicativo: análisis, usos y valor profundo. RedELE 6. http://www.educacion.es/redele/revista6/MatteBon.pdf. Last access 25 March 2011.

Moreno de Alba, José G. 1993. El español en América. México: Fondo de Cultura Económica.

Nuyts, Jan. 2001. Epistemic Modality, Language, and Conceptualization: A cognitive-pragmatic perspective. Amsterdam, Philadelphia: Benjamins.

Other \& Author. 2018.

Palmer, Frank R. 2001. Mood and Modality. Cambridge: Cambridge University Press.

R Development Core Team. 2019. R: A language and environment for statistical computing. Version 3.4.2 (Kite-Eating Tree). R Foundation for Statistical Computing, Vienna, Austria. http://www.Rproject.org. Last access 1 July 2019.

Rivero, María Luisa. 2014. Spanish inferential and mirative futures and conditionals: An evidential gradable modal proposal. Lingua 151(B). 197-215.

Rodríguez Rosique, Susana. 2019. El futuro en español. Tiempo, conocimiento, interacción. Berlin: Peter Lang. 
Sedano, Mercedes. 2006. Importancia de los datos cuantitativos en el estudio de las expresiones de futuro. Revista Signos 39. 283-296.

Traugott, Elizabeth C. \& Graeme Trousdale. 2013. Constructionalization and constructional changes. Oxford: Oxford University Press. 